\title{
The $52^{\circ}-55^{\circ}$ segment of the Bacillus subtilis chromosome: a region devoted to purine uptake and metabolism, and containing the genes cotA, gabP and guaA and the pur gene cluster within a 34960 bp nucleotide sequence
}

\author{
Rainer Borriss, Steffen Porwollik and Ragnar Schroeter \\ Author for correspondence: Rainer Borriss. Tel: +49 302093 8137. Fax: +49 3020938127. \\ e-mail: rainer=borriss@,rz.hu-berlin.de
}

Humboldt Universităt Berlin, Institut fur Biologie, Bakteriengenetik, Chausseestr. 117, D-10115 Berlin, Germany

\begin{abstract}
Within the framework of the international project for sequencing the entire Bacillus subtilis genome, we have determined the complete sequence of the segment flanking the purE-D gene cluster $\left(55^{\circ}\right)$ as far as cotA $\left(52^{\circ}\right)$. This segment ( $34960 \mathrm{bp}$ ) contains, as well as 12 genes already identified as part of the pur operon, 17 putative ORFs and one partial one. Two of them (gabP and guaA) are known B. subtilis genes. The gene product of cotA (formerly pig) shows significant similarity to oxidoreductases (phenoxazine synthase and bilirubin oxidase). The putative products of ORFs yeaB (Czd protein), yeaC (MoxR), yebA (CNG-channel and CGMP-channel proteins from eukaryotes), yebB (hypothetical 32.9 kDa protein of Escherichia coli), yecA (amino acid permease) and yecB (adenine deaminase) were similar to proteins in data banks.
\end{abstract}

Keywords: Bacillus subtilis, genome sequencing, $\cot A$, gua $A, \operatorname{pur} F$

\section{INTRODUCTION}

The chromosomal region of Bacillus subtilis 168 extending from $52^{\circ}$ to $55^{\circ}$, between $\cot A$ and the pur gene cluster (Anagnostopoulos et al., 1993), has been shown to contain many genes involved in purine uptake and metabolism. Most of these have been found clustered within a polycistronic operon (Ebbole \& Zalkin, 1987; Saxild \& Nygaard, 1987, 1988; Mäntsälä \& Zalkin, 1992). The region lies about $700 \mathrm{~kb}$ downstream from the zero position of the $B$. subtilis physical map and approximately $670 \mathrm{~kb}$ downstream from the replication origin oriC (Itaya \& Tanaka, 1991). As part of the cooperative B. subtilis genome project between European and Japanese laboratories to determine the entire nucleotide sequence of the $B$. subtilis genome, we have sequenced and analysed $34960 \mathrm{bp}$ of the region flanking the pur gene cluster. The sequence and the genetic organization of the $13160 \mathrm{bp}$ region containing the pur gene cluster have been reported by Ebbole \& Zalkin (1987).

In this contribution, we summarize the main features of 18 ORFs identified $5^{\prime}$ and $3^{\prime}$ from the pur operon. In

Abbreviation: LR PCR, Long Range PCR.

The GenBank accession numbers for the sequences reported in this paper are U51115 (HUB5), J02732 (HUB1) and $J 02732$ (HUB2A). addition, we present an updated physical map of the $60 \mathrm{~kb}$ region which has been assigned to our laboratory by the EU genome sequencing project.

\section{METHODS}

Bacterial strains, plasmids and phages. B. subtilis strain 1 A1 (Marburg 168, $\operatorname{tr} p C 2$ ) was chosen as our target strain. Escherichia

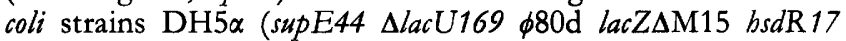
recA1 gyr $A 96$ thi-1 rel $A 1 \mathrm{~F}^{-}$), TP611 (cya pcn, Glaser et al., 1993) and JM101 (rec $A 1$ supE44 end $A 1$ bsdR 17 gyr $A 96$ rel $A 1$ thi-1

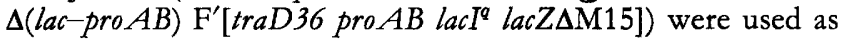
cloning hosts for plasmids rescued from $B$. subtilis and M13mp18 phage clones, respectively.

Plasmids pDE64 and pDE81, containing fragments of the pur operon, were obtained from $\mathrm{H}$. Zalkin (Ebbole \& Zalkin, 1987); pNEXT38 containing the NotI-763 flanking region was obtained from M. Itaya (Itaya \& Tanaka, 1991) and plasmids pGA13 and pGA14, containing parts of the gua $A$ gene region, were kindly given by P. Mäntsälä (Mäntsälä \& Zalkin, 1992). Plasmid pDIA5304, used as an integration vector, was constructed by P. Glaser (Glaser et al., 1993).

Cloning and DNA techniques. DNA from phages and plasmids was isolated by standard procedures according to Sambrook $e t$ al. (1989). Minimal salts medium used for DNA transformation of B. subtilis was that of Anagnostopoulos \& Spizizen (1961). Plasmid rescue was done according to Glaser et al. (1993). Long Range PCR (LR PCR) was carried out using the Expand Long 
Template PCR System (Boehringer Mannheim), according to the supplier's instructions.

Sequencing and data handling. LR PCR fragments and plasmid inserts were digested with DNase I to obtain fragments of $0.5-2 \mathrm{~kb}$. The fragments were blunt-end repaired with T4 DNA polymerase $(30 \mathrm{~min})$ and Klenow polymerase $(15 \mathrm{~min})$ and ligated into dephosphorylated M13mp18 or pUC18 vectors. The clones were sequenced using an automatic sequencing system (Autoread Sequencing Kit, Pharmacia). Sequencing data were evaluated using the software packages GENE SKIPPER V1.2 (EMBL) and PCGENE V6.85 (IntelliGenetics). Homology searches were performed using programs BLAST and FASTA. Program BLASTX was especially valuable for detecting frame shifts in ORFs. Remaining gaps between the contigs were filled by primer walking.

\section{RESULTS AND DISCUSSION}

\section{Cloning and mapping of the sequence flanking the pur operon}

A 517 bp DNA fragment from the purE gene was amplified, cloned into pDIA5304 and integrated into $B$. subtilis 168. Chromosomal DNA isolated from four transformants was restricted with EcoRI. The religated DNA was transformed into E. coli TP611. Only one chloramphenicol-resistant clone containing plasmid pSP303 was obtained. Sequencing of the $5.5 \mathrm{~kb}$ insert of pSP303 revealed two ORFs ( $y e b B$ and $y e b C$ ) encoding putative membrane-associated proteins. ORF yebC was found to be interrupted at amino acid 213 by an IS1A element. The corresponding DNA sequence obtained by LR PCR amplification of $B$. subtilis chromosomal DNA does not contain the IS element, suggesting that the insertion was due to cloning in E. coli. Further cloning of the region $5^{\prime}$ from pur was carried out by plasmid rescue using a $1 \mathrm{~kb}$ HincII fragment derived from plasmid pGA14 (Mäntsälä \& Zalkin, 1992). The resulting plasmid, pSP312, contained the gua sequence and regions $5^{\prime}$ to gua $A$. The LR PCR fragments containing $\cot A, g a b P$ and gua $A$ were also used for sequencing of a $15 \mathrm{~kb}$ region flanking the $5^{\prime}$ end of the pur operon. The distances determined between the known genetic markers $\cot A$ $\left(52^{\circ}\right)$, gua $A\left(54^{\circ}\right)$ and purE $\left(55^{\circ}\right)$ were shorter than expected: $\cot A-9 \mathrm{~kb}-$ gua $A-6 \mathrm{~kb}$-purE (Figs 1 and 2).

To clone the B. subtilis DNA downstream from the pur gene cluster, the $1.6 \mathrm{~kb}$ HindIII-NotI fragment obtained from plasmid pNEXT38 was used for the plasmid rescue strategy described above. A DNA fragment covering $15.5 \mathrm{~kb}$ of the region between NotI-763 and the $3^{\prime}$ end of the pur gene cluster was obtained (pRS205). The gap between the pur sequence and pRS205 was closed by applying LR PCR using oligonucleotide primers purRout and $205 \mathrm{P} 1$. The amplified $4.6 \mathrm{~kb}$ fragment (PCR209) was found to cover the remaining gap between pur and pRS205, suggesting that the distance between the purE- $D$ gene cluster and NotI-763 is $20 \mathrm{~kb}$.

According to the physical map, the NotI-763 restriction site lies $68 \mathrm{~kb}$ downstream of $\cot A$ which has been located $695 \mathrm{~kb}$ from the zero position of the B. subtilis chromosome (Itaya \& Tanaka, 1991). Our data indicate that the distance between $\cot A$ and Not $\mathrm{I}-763$ is only $49 \cdot 5 \mathrm{~kb}$. We also cloned a LR PCR fragment with the $3^{\prime}$ flanking region of NotI-763 containing the opuE gene. opuE stands for osmoprotectant uptake and it encodes the OpuE protein (493 aa, $M_{\mathrm{r}}$ 53400) which complements $E$. coli strains with defects in the proline transport system (von Blohm et al., 1996). The whole region cloned in this study has the gene order cotA-gabP-guaA-purE-D-opuE and consists of $60.5 \mathrm{~kb}$ (Fig. 1).

\section{Identification of ORFs and gene organization in the 34960 bp region}

Evaluation of putative coding regions revealed $18 \mathrm{ORFs}$, besides the 12 previously reported genes of the pur cluster. One of them, yea $A$, is partial. Each ORF is preceded by a

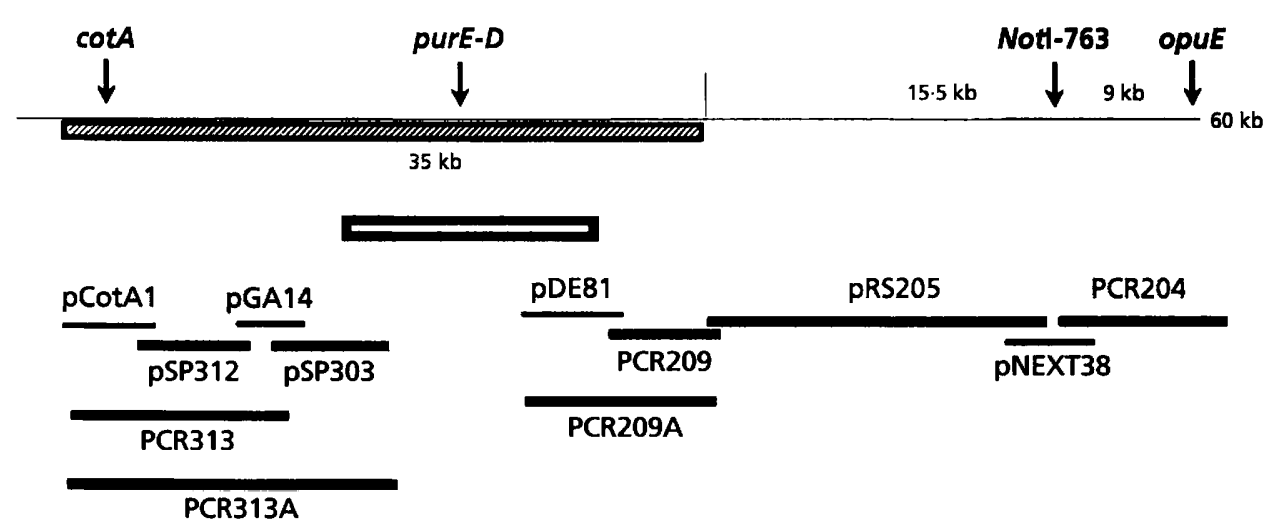

Fig. 1. Genetic map of the cotA-opuE region located at $705-765 \mathrm{~kb}$ according to the physical map of Itaya \& Tanaka (1991). The cloned region, $60 \mathrm{~kb}$, is indicated by a thin line. The sequenced area is hatched. The sequence covering the purE-D gene cluster (Ebbole \& Zalkin, 1987) is indicated by a box. Plasmids and LR PCR fragments obtained in this study are also indicated. 


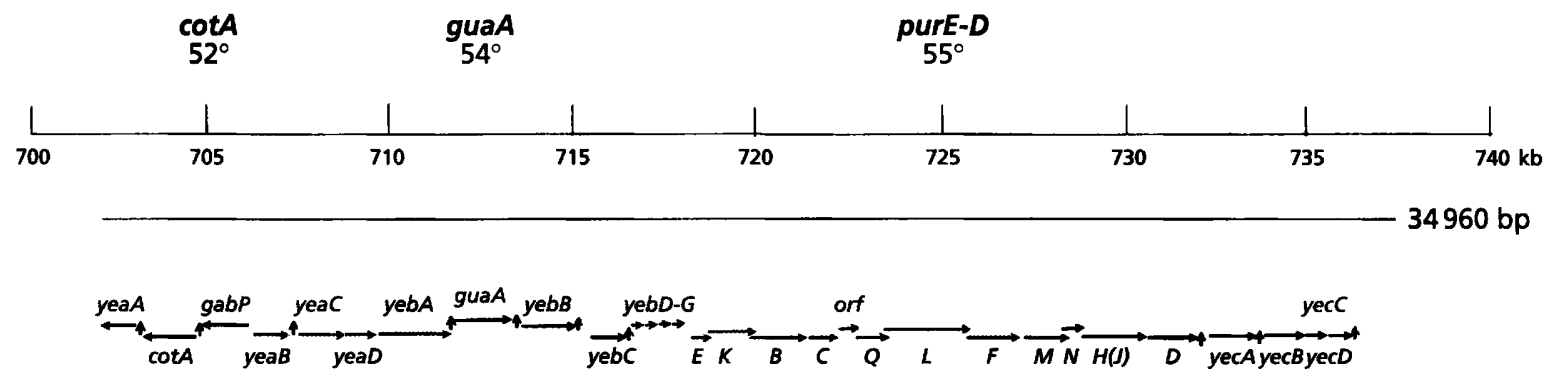

Fig. 2. ORFs identified within the cotA-purE-D region covering $34960 \mathrm{bp}$. Their positions according to the genetic map (Anagnostopoulos et al., 1993), the physical map (Itaya \& Tanaka, 1991) and the direction of transcription are also indicated. Factor-dependent termination signals are shown by vertical arrows. Genes previously identified are in bold.

Table 1. Putative ORFs in the $52^{\circ}-55^{\circ}$ region of the $B$. subtilis chromosome

\begin{tabular}{|c|c|c|c|c|}
\hline ORF* & Endpoints (nt) & $\mathbf{G}+\mathbf{C}(\%)$ & $\begin{array}{c}\text { Codon } \\
\text { usage } \\
\text { (GC-bias) }\end{array}$ & $\begin{array}{l}\text { SD consensus sequence } \\
\text { (upper case) and } \\
\text { initiation codon (bold) }\end{array}$ \\
\hline yea $A$ & $1<798$ & $39 \cdot 1$ & $41 \cdot 7$ & AcAAAGGAGcTttttATG \\
\hline $\cot A$ & $899<2431$ & $47 \cdot 6$ & $48 \cdot 1$ & AgAtaAGGacagATG \\
\hline$g a b P$ & $2586<3992$ & $47 \cdot 0$ & $53 \cdot 4$ & AAAGGAGGTaActtATG \\
\hline yeaB & $4390>5259$ & $45 \cdot 4$ & $45 \cdot 7$ & AGGAGGTtttgtATG \\
\hline yea $C$ & $5415>6734$ & $48 \cdot 1$ & $48 \cdot 6$ & AGGAGGaaaataATG \\
\hline yeaD & $6761>7570$ & $48 \cdot 9$ & $45 \cdot 9$ & AAAcGAGcaTGAcgATG \\
\hline$y e b A$ & $7770>9734$ & $45 \cdot 4$ & $47 \cdot 6$ & AGGaTGAgGTG \\
\hline guaA & $9970>11509$ & $45 \cdot 8$ & $46 \cdot 9$ & gtGAGGTGAcaaccATG \\
\hline yebB & $11973>13200$ & $46 \cdot 0$ & $46 \cdot 2$ & GAAgGGAGtcaAatagctTTG \\
\hline yebC & $13415>14216$ & $43 \cdot 0$ & $39 \cdot 2$ & GAtGGAGtTGcTgacATG \\
\hline$y e b D$ & $14377>14596$ & $40 \cdot 2$ & $40 \cdot 3$ & AAGGAGGaTGgacATG \\
\hline yebE & $14765>15001$ & $40 \cdot 0$ & $51 \cdot 6$ & AGGgGGaTGAataaATG \\
\hline$y e b F$ & $15046>15309$ & $47 \cdot 1$ & $52 \cdot 8$ & GGcGcTtggctatattATG \\
\hline$y e b G$ & $15312>15507$ & $39 \cdot 9$ & $45 \cdot 5$ & AGGAGaattaaagaataATG \\
\hline purE & $15832>16319$ & $50 \cdot 1$ & $47 \cdot 9$ & AGAAGGtGGgGAacagaATG \\
\hline purK & $16314>17450$ & $47 \cdot 1$ & $49 \cdot 4$ & AGAAAGcAGTGATCagcTTG \\
\hline purB & $17449>18742$ & $45 \cdot 6$ & $45 \cdot 6$ & GGAGGacaagcagaATG \\
\hline purC & $18818>19540$ & $49 \cdot 1$ & $46 \cdot 4$ & AGGAGGccttccGTG \\
\hline purQ & $19787>20467$ & $47 \cdot 4$ & $47 \cdot 6$ & AGGAGGTagtcgcacaGTG \\
\hline purL & $20454>22679$ & $48 \cdot 3$ & $45 \cdot 4$ & GGAGGGAaactcATG \\
\hline purF & $22658>24085$ & $49 \cdot 7$ & $51 \cdot 9$ & GAAAAAAGctatcccATG \\
\hline purM & $24189>25226$ & $49 \cdot 2$ & $48 \cdot 1$ & AAAGGAGTGAataggATG \\
\hline purN & $25226>25810$ & $47 \cdot 3$ & $47 \cdot 4$ & GGcGGTGcggcactttcATG \\
\hline purH $(J)$ & $25810>27345$ & $48 \cdot 1$ & $48 \cdot 3$ & aGAGGTGAaaaggcATG \\
\hline purD & $27364>28629$ & $48 \cdot 7$ & $46 \cdot 0$ & AAGGGGa'TGAaaacgacGTG \\
\hline yec $A$ & $29236>30483$ & $48 \cdot 5$ & $49 \cdot 5$ & AGAgAGGgGGcatcATG \\
\hline$y e c B$ & $31188>32470$ & $46 \cdot 7$ & $51 \cdot 6$ & AaActGGcGGaatatGTG \\
\hline yecC & $32498>32989$ & $47 \cdot 7$ & $50 \cdot 9$ & AAaGAGGctATG \\
\hline$y e c D$ & $33063>33638$ & $41 \cdot 2$ & $37 \cdot 8$ & GGAGcTGccCgattatATG \\
\hline
\end{tabular}

* ORFs with known function are shown in bold letters.

putative Shine-Dalgarno (SD) sequence (McLaughlin $e t$ al., 1981) 5-20 bp upstream from the putative start codon ATG, TTG or GTG. The shortest ORF is yebG with 66 codons, the longest is yeb $A$ with 655 codons. Considerable variation in codon usage (GC-bias) ranging from $37.8 \%$ $(y e c D)$ to $51 \cdot 6 \%(y e c B)$ was detected (Table 1$)$. With the exception of the first three $(y e a A, \cot A, g a b P)$ the ORFs are directed towards the terminus of replication. Factorindependent terminator structures $3^{\prime}$ to the translation stop signal(s) were found after $\cot A(\Delta G-13.6 \mathrm{kcal})$, gabP $(\Delta G-4.8 \mathrm{kcal})$, yeaB-yeaC-yeaD-yebA-gua $A(\Delta G$ $-15.0 \mathrm{kcal})$, yebB $(\Delta G-23.4 \mathrm{kcal})$, yeb $C(\Delta G-21.6 \mathrm{kcal})$, 
Table 2. Similarity of the predicted ORF products with entries of the databases

\begin{tabular}{|c|c|c|c|c|c|}
\hline ORF & $\begin{array}{l}\text { size } \\
\text { (aa) }\end{array}$ & $\begin{array}{c}\text { Database } \\
\text { accession } \\
\text { no.* }\end{array}$ & Function/similarity $\dagger$ & $\begin{array}{l}\text { BLAST } \\
\text { score }\end{array}$ & Match $(\%) \ddagger$ \\
\hline \multirow[t]{4}{*}{$\cot A$} & 510 & PIR : P07788 & Spore coat protein A (B. subtilis) & 196 & $100(37)$ \\
\hline & & GB: U04283 & Phenoxazine synthase (Streptomyces antibioticus) & 182 & $35 \cdot 1(313)$ \\
\hline & & PIR: B48521 & Bilirubin oxidase (Myrotbecium verrucaria) & 146 & $28 \cdot 3(431)$ \\
\hline & & SP: P26648 & SufI protein $(E$. coli $)$ & 177 & $27 \cdot 3(300)$ \\
\hline \multirow[t]{2}{*}{$g a b P$} & 469 & SP: P46349 & $\gamma$-Amino butyrate permease (B. subtilis) & 2530 & $100(469)$ \\
\hline & & SP: P25527 & $\gamma$-Amino butyrate permease (E. coli) & 737 & $48 \cdot 6(444)$ \\
\hline \multirow[t]{3}{*}{ yeaB } & 290 & SP: P46348 & Hypothetical protein YDXT (B. subtilis) & 1367 & $100(276)$ \\
\hline & & SP: P32159 & Hypothetical $32.9 \mathrm{kDa}$ protein YIIP (E. coli) & 146 & $22 \cdot 0(195)$ \\
\hline & & SP: P13512 & Cation efflux system Czd protein (Alcaligenes eutrophus) & 101 & $22 \cdot 0(99)$ \\
\hline \multirow[t]{3}{*}{ yeaC } & 320 & GB: D64003 & Hypothetical protein SYCSLLE_70 (Synechocystis sp.) & 353 & $50 \cdot 1(280)$ \\
\hline & & PIR : S43189 & Hypothetical protein_2 (Pseudomonas aeruginosa) & 308 & $54 \cdot 1(170)$ \\
\hline & & SP: P29901 & MoxR protein (Paracoccus denitrificans) & 130 & $25 \cdot 7(272)$ \\
\hline \multirow[t]{2}{*}{$y e b A$} & 655 & GB: X89598 & Photoreceptor CNG-channel protein (Gallus gallus) & 91 & $36 \cdot 0(44)$ \\
\hline & & SP: P29974 & Photoreceptor cGMP-channel protein (Mus musculus) & 90 & $38 \cdot 0(44)$ \\
\hline \multirow[t]{2}{*}{ gua $A$} & 513 & SP: P29727 & GMP synthetase (B. subtilis) & 2658 & $98 \cdot 0(513)$ \\
\hline & & SP: P44335 & GMP synthetase (Haemopbilus infuenzae) & 557 & $54 \cdot 5(489)$ \\
\hline \multirow[t]{2}{*}{$y e b B$} & 440 & SP: P31440 & Hypothetical $49.9 \mathrm{kDa}$ protein YICO (E. coli) & 377 & $41 \cdot 2(440)$ \\
\hline & & SP: P31466 & Hypothetical $46.9 \mathrm{kDa}$ protein YIEG (E. coli) & 357 & $40 \cdot 2(440)$ \\
\hline purE & 162 & & AIR carboxylase I (B. subtilis) & & \\
\hline purK & 379 & & AIR carboxylase II (B. subtilis) & & \\
\hline purB & 431 & & Adenylosuccinate lyase (B. subtilis) & & \\
\hline \multirow[t]{2}{*}{ purC } & 241 & & Phosphoribosylaminoimidazole- & & \\
\hline & & & succinocarboxamide synthetase (B. subtilis) & & \\
\hline $\operatorname{pur} Q$ & 227 & & FGAM synthetase I (B. subtilis) & & \\
\hline purL & 742 & & FGAM synthetase II (B. subtilis) & & \\
\hline purF & 476 & & Amidophosphoribosyltransferase (B. subtilis) & & \\
\hline purM & 346 & & AIR synthetase (B. subtilis) & & \\
\hline $\operatorname{purN}$ & 195 & & GAR formyltransferase (B. subtilis) & & \\
\hline \multirow[t]{2}{*}{ pur $H(J)$} & 512 & & Phosphoribosylaminoimidazole-carboxamide & & \\
\hline & & & formyltransferase/IMP cyclohydrolase & & \\
\hline purD & 422 & & GAR synthetase & & \\
\hline \multirow[t]{2}{*}{$\operatorname{yec} A$} & 433 & SP: P25527 & $\gamma$-Amino butyrate permease $(E$. coli $)$ & 119 & $21 \cdot 8(308)$ \\
\hline & & SP: P40812 & L-Asparagine permease (Salmonella typhimurium) & 115 & $20 \cdot 1(334)$ \\
\hline yec $B$ & 427 & SP: P39761 & Adenine deaminase (B. subtilis) & 118 & $22 \cdot 2(436)$ \\
\hline
\end{tabular}

* SP, SwissProt; GB, GenBank.

† Identical proteins (100\% match) are shown in italics.

$\ddagger$ The number of amino acids over which the percentage match was determined is shown in parentheses.

yebD-yebE-yebF-yebG $(\Delta G-13 \cdot 8 \mathrm{kcal})$, the pur gene cluster $(\Delta G-21.6 \mathrm{kcal})$, yec $A(\Delta G-20.2 \mathrm{kcal})$ and $y e c B(\Delta G$ $-16.8 \mathrm{kcal})$. These results indicate that both polycistronic and monocistronic transcripts are present (Fig. 2).

\section{Similarity analysis of the putative gene products to known proteins}

Results of similarity analyses are summarized in Table 2. Besides the known genes of the pur operon, genes $\cot A$, gabP and gua $A$ were identified within the 34960 bp contig. Five putative gene products show homology to other known or hypothetical proteins in the data banks.
cotA. $\cot A$, mapped at $52^{\circ}$, encodes the $65 \mathrm{kDa}$ coat polypeptide which is identical to the Pig protein. The molecular mass deduced from the putative amino acid sequence is $58 \mathrm{kDa}$. The CotA protein transcribed by $\mathrm{E} \sigma^{\kappa}$ is responsible for the brown colour of sporulating cells but is not required for spore formation (Donovan et al., 1987). The high homology to phenoxazinone synthase, bilirubin oxidase (EC 1.3.3.5) and the manganese oxidizing protein from Leptothrix discophora suggests a putative function as an oxidase. Homology was also found to the sufI gene product of $E$. coli which acts as a suppressor of the $f$ ts $I$ allele involved in cell division and chromosome segregation. 
gabP. This gene encodes $\gamma$-aminobutyrate permease as a monocistronic transcript. The primary sequence suggests the presence of 12 transmembrane helices (program RAOARGOS). The $48.6 \%$ identity with GabP from Eschericbia coli confirms the function as GABA permease.

Two of the ORFs (yeaB and yeb $A$ ) identified between $g a b P$ and gua $A$ encode proteins containing transmembranespanning helices (Table 2).

guaA. gua $A$, mapped at $54^{\circ}$, encodes GMP synthetase (Mäntsälä \& Zalkin, 1992). The enzyme is involved in purine nucleotide biosynthesis (XMP $\rightarrow$ GMP). Resequencing revealed six differences in the nucleotide sequence which lead to changes in amino acid sequence. Most striking are $\mathrm{H}_{168} \rightarrow \mathrm{Y}, \mathrm{S}_{196} \rightarrow \mathrm{C}$ and $\mathrm{R}_{262} \rightarrow \mathrm{A}$, since these substitutions improve the similarity to other GMP synthetases.

purE-D. This region, mapped at $55^{\circ}$, contains a cluster of 12 genes that encode enzymes for de novo synthesis of purine nucleotides. The cluster is a single transcription unit and is organized into three groups of overlapping genes followed by the last gene: purEKB-purC(orf)QLFpurMNH( $(J)$-purD (Ebbole \& Zalkin, 1987).

Mutants resistant to 8-azaguanine ( $p b u G$ mutants) appear to be defective in hypoxanthine and guanine transport (Saxild \& Nygaard, 1987). They were mapped between gua $A$ and the pur gene cluster (Saxild \& Nygaard, 1988). Two of the ORFs identified in this region encoded membrane proteins which might be involved in transport of these compounds: yebB encodes a transmembrane protein with five membrane-spanning helices; and yebC encodes a transmembrane protein with one membranespanning and one membrane-associated helix motif. However, since similarity to proteins with known function was not detectable (Table 2), complementation analysis with DNA fragments spanning gua $A$ and purE will be necessary to identify the $p b u G$ locus in this area.

\section{ACKNOWLEDGEMENTS}

Strain E. coli TP611 and integration plasmid pDIA5304 were obtained from P. Glaser. We thank Dr M. Itaya for providing plasmids pCotA1, pNEXT38 and pNEXT11. Plasmids pGA13 and pGA14 were kindly provided by $\operatorname{Dr}$ P. Mäntsälä. Plasmids pDE64 and pDE81 were obtained from Dr H. Zalkin. We are very grateful to Drs E. Bremer and S. Fisher for providing data prior to publication. This work was supported by a Grant-inAid from the EU contract BIO-CT 94.

\section{REFERENCES}

Anagnostopoulos, C. \& Spizizen, J. (1961). Requirements for transformation of Bacillus subtilis. J Bacteriol 81, 741-746.

Anagnostopoulos, C., Piggot, P. J. \& Hoch, J. A. (1993). The genetic map of Bacillus subtilis. In Bacillus subtilis and Other Grampositive Bacteria: Biochemistry, Physiology and Molecular Genetics, pp. 425-461. Edited by A. L. Sonenshein, J. A. Hoch \& R. Losick. Washington, DC: American Society for Microbiology.

von Blohm, C., Kappes, R. \& Bremer, E. (1996). Osmoregulation in Bacillus subtilis: identification of an osmotically regulated proline uptake system. In Abstracts of the VAAM Spring Meeting, Bayreuth 24-27 March 1996, p. 45

Donovan, W., Zheng, L., Sandman, K. \& Losick, R. (1987). Genes encoding spore coat polypeptides from Bacillus subtilis. $J$ Mol Biol 196, 1-10.

Ebbole, D. J. \& Zalkin, H. (1987). Cloning and characterization of a 12-gene cluster from Bacillus subtilis encoding nine enzymes for de novo purine nucleotide synthesis. J Biol Chem 262, 8274-8287.

Glaser, P., Kunst, F., Arnaud, M., Coudart, M.-P., Gonzales, W., Hullo, M.-F., lonescu, M., Lubochinsky, B., Marcelino, L., Moszer, I., Presecan, E., Santana, M., Schneider, E., Schweizer, J., Vertes, A., Rapoport, G. \& Danchin, A. (1993). Bacillus subtilis genome project: cloning and sequencing of the $97 \mathrm{~kb}$ region from $325^{\circ}$ to $333^{\circ}$. Mol Microbiol 10, 371-384.

Itaya, M. \& Tanaka, T. (1991). Complete physical map of the Bacillus subtilis 168 chromosome constructed by a gene-directed mutagenesis method. $J$ Mol Biol 220, 631-648.

McLaughlin, J. R., Murray, C. L. \& Rabinowitz, J. C. (1981). Unique features in the ribosome-binding site sequence of the Grampositive Staphylococcus aureus $\beta$-lactamase gene. $J$ Biol Chem 256, 11183-11291.

Măntsălä, P. \& Zalkin, H. (1992). Cloning and sequence of Bacillus subtilis pur $A$ and gua $A$, involved in the conversion of IMP to AMP and GMP. $J$ Bacteriol 174, 1883-1890.

Sambrook, J., Fritsch, E. F. \& Maniatis, T. (1989). Molecular Cloning: a Laboratory Manual. Cold Spring Harbor, NY: Cold Spring Harbor Laboratory.

Saxild, H. H. \& Nygaard, P. (1987). Genetic and physiological characterization of Bacillus subtilis mutants resistant to purine analogs. J Bacteriol 169, 2977-2983.

Saxild, H. H. \& Nygaard, P. (1988). Gene-enzyme relationships of the purine biosynthesis pathway in Bacillus subtilis. Mol Gen Genet 211, 160-167.

Received 18 April 1996; revised 8 July 1996; accepted 17 July 1996. 